\title{
The Role of Chlamydia pneumoniae in the Atherosclerotic Process of Patients under 50 Years of Age Who Underwent Coronary Artery Bypass Graft Surgery
}

\author{
Selami Gurkan ${ }^{1}$, Suat Canbaz ${ }^{2}$, Ozcan Gur $^{1 *}$, Serhat Huseyin ${ }^{2}$, Turan Ege ${ }^{2}$, Enver Duran ${ }^{2}$ \\ ${ }^{1}$ Department of Cardiovascular Surgery, Namik Kemal University Hospital, Tekirdağ, Turkey \\ ${ }^{2}$ Department of Cardiovascular Surgery, Trakya University Hospital, Edirne, Turkey \\ Email: *ozcangur@hotmail.com
}

Received July 13, 2013; revised August 10, 2013; accepted August 24, 2013

Copyright (C) 2013 Selami Gurkan et al. This is an open access article distributed under the Creative Commons Attribution License, which permits unrestricted use, distribution, and reproduction in any medium, provided the original work is properly cited.

\begin{abstract}
Background: To evaluate the presence of $C$. pneumoniae DNA in the tissues and C. pneumoniae DNA antibodies in the blood samples of patients who underwent $C A B G$ surgery. Material and Methods: Fifty-one patients $<50$ years of age were included in the study, and analyzed in two groups according to the intimal thickness of aorta. C. pneumoniae DNA was evaluated in the tissues collected from the atrium, left internal thoracic artery and ascending aorta of patients. Results: Although, C. pneumoniae DNA was negative in the atrial and left internal thoracic artery tissues of all patients, it was positive in the tissues obtained from the ascending aortas of twelve patients. C. pneumoniae DNA positivity was significantly higher in patients with increased aortic intimal thickness compared to those without increased aortic thickness. Conclusion: The question whether C. pneumoniae is triggering atherosclerosis or is involved as a superinfection could not be clarified.
\end{abstract}

Keywords: Bypass Surgery; Chlamydia pneumoniae; Atherosclerosis

\section{Introduction}

Despite improvements in the treatment of cardiovascular diseases, people still die because of these diseases, although in later life [1]. Studies show that mortality of cardiovascular diseases worldwide will increase from $28.9 \%$ in 1999 to $36.3 \%$ in 2020 [2].

Risk factors such as smoking, hypertension, dyslipidemia, diabetes mellitus, a positive family history of cardiovascular disease, male gender and age can explain only $50 \%$ of patients with coronary artery atherosclerosis. Other risk factors like chronic infections are also known to cause atherosclerosis [3].

Clinical data and animal models suggested that common chronic infections, including Chlamydia pneumoniae, cytomegalovirus, herpes virus, and Helicobacter pylori might trigger atherosclerosis [4]. However, recent studies revealed an association between $C$. pneumoniae antibodies and coronary heart disease (CHD), C. pneumoniae, an intracellular pathogen, is one of the most common causes of community-acquired respiratory tract

${ }^{*}$ Corresponding author. infections. Studies showed that C. pneumoniae DNA positivity was detected in $25 \%-38 \%$ of occluded saphenous vein grafts and $30 \%$ of internal thoracic artery (ITA) grafts after coronary artery bypass graft (CABG) surgery $[5,6]$.

The possibility of an etiological relationship between the pathogenesis of atherosclerosis and infectious diseases was first raised by Sir William Osler in 1908. However, the association between C. pneumoniae and atherosclerosis was first argued in 1990 s because of a series of sero-epidemiological studies conducted in Finland [7]. In the subsequent studies, many authors reported the presence of a positive association between $C$. pneumoniae and coronary atherosclerosis [8,9]. Various hypotheses were advanced to explain the association between coronary artery disease and C. pneumonia $[10$ 13].

From this point of view, we suggested that the demonstration of C. pneumoniae DNA positivity in the young age group who underwent CABG surgery would assist in the clarification of atherosclerosis etiopathogenesis. For this purpose, we evaluated the presence of C. pneumoniae DNA in the tissues and C. pneumoniae DNA anti- 
bodies in the blood samples of patients who underwent CABG surgery.

\section{Methods}

The study was approved by the Ethical Committee of the Faculty of Medicine of Trakya University. Written informed consents were obtained from the participants or legal representatives of the patients before entering the study. Fifty-one patients $<50$ years of age, who underwent elective primary isolated coronary bypass surgery were included in the study and the patients were analyzed in two groups determined according to the intimal thickness of the aorta. Tissue samples, $3-5 \mathrm{~mm}$ in size, obtained from the right atrium, aorta, and left ITAs of the patients and blood samples were analyzed. According to the Modified Wareing classification used by Matsuyama et al. [14], ascending aorta were divided into three parts and atherosclerotic changes were classified as none, moderate and severe, based on the extent of intimal thickening [15]. Ascending aortic wall thickness was measured intraoperatively by transesophageal echocardiographic measurements. Patients were divided into two groups according to the aortic wall thickness. Group 1 comprised 23 patients with an ascending aortic intimal thickness $<2 \mathrm{~mm}$, and Group 2 involved 28 patients with an ascending aortic intimal thickness $\geq 2 \mathrm{~mm}$. In addition to the preoperative characteristics, C. pneumoniae immunoglobulin (Ig)G, IgA, IgM antibodies (in 1/100 dilution), lipid profiles, C-reactive protein (CRP) levels and operative data were recorded. Serum samples positive for $\mathrm{IgG}, \operatorname{IgA}$ and $\operatorname{IgM}$ at $1 / 100$ dilution were considered positive for $C$. pneumoniae infection. Serum and tissue samples were studied in the microbiology and molecular genetics laboratory.

\subsection{Study Protocol}

Serum samples were studied with the $C$. pneumoniae EUROIMMUN IIFT (FK 2192-1005) kit at 1/100 dilution for the detection of $C$. pneumoniae $\mathrm{IgG}, \mathrm{IgA}$ and IgM antibodies. All tissue specimens were dissected in the operating room and placed in microcentrifuge tubes, containing Tris-ethylenediaminetetraacetic acid buffer (TE buffer) at $-4^{\circ} \mathrm{C}$ for the extraction of DNA. Tissue DNA was extracted by DNA isolation kit (QIAamp DNA Mini Kit, QIAGEN). All of the extracted DNA samples were kept at $-20^{\circ} \mathrm{C}$ until analysis. Samples were studied in a real-time polymerase chain reaction (PCR) device (iCycler iQ, Biorad, USA) by C. pneumoniae QLS-2.0 DNA Detection Kit (fluorine). By this method, 79 base pairs of major outer-membrane protein (MOMP) gene of the $C$. pneumoniae genome were replicated in the realtime PCR device [16]. The product of PCR was monitored during the reaction via a fluorescent dye named
SYBR-green.

\subsection{Statistical Analysis}

Statistical evaluation was performed using the STATISTICA AXA statistical software numbered AXA507C775506FAN3. The Kolmogorov-Smirnov test was used to test for normal distribution. The $t$ test was used to compare the differences between the groups with normal distribution and the Mann Whitney U test was used to compare the differences between the groups with nonnormal distribution. The Pearson's $\chi^{2}$ test was used for qualitative data, and the Fisher's $\chi^{2}$ test was used when the expected value in one or more cells was less than 5 . As descriptive statistics, arithmetic mean (standard deviation) values were given for variables with normal distribution; and median (min-max) values were given for those with non-normal distribution. Statistical significance was set at $\mathrm{p}<0.05$.

\section{Results}

Fifty-one patients (44 males and 7 females) were enrolled in the study. Mean age of the patients was $45.5 \pm$ 4.2 years (range, 35 - 50 years) and the mean left ventricular ejection fraction was $54.8 \% \pm 11.6 \%$ (range 18 72). The patients were analyzed in two groups according to the thickness of the ascending aortic wall; Group 1 (intimal thickness $<2 \mathrm{~mm} ; \mathrm{n}=23$ ) and Group 2 (intimal thickness $\geq 2 \mathrm{~mm} ; \mathrm{n}=28$ ). Left ITA graft was used in all patients. One patient in Group 1 had chronic renal failure and one patient in Group 2 had peripheral arterial disease. The demographic characteristics and operative data of the patients according to study groups are listed in Table 1. No significant difference was found between the two groups with respect to age, sex, body mass index, presence of diabetes mellitus, hypertension, chronic renal failure, peripheral arterial disease, smoking history, total cholesterol levels, medical history of unstable angina pectoris and myocardial infarction, and family history of cardiac disease $(\mathrm{p}>0.05)$.

No significant difference was observed between the two groups in terms of $C$. pneumoniae $\mathrm{IgG}, \mathrm{IgA}$ and $\mathrm{IgM}$ antibody positivity rates at $1 / 100$ dilution ( $\mathrm{p}>0.05)$. $C$. pneumoniae $\operatorname{IgG}, \operatorname{IgA}$ and $\operatorname{IgM}$ antibody positivity rates are given in Table 2. IgA antibodies were positive in $87 \%(\mathrm{n}=20)$ of patients in Group 1 and $85.7 \%$ of patients in Group $2(\mathrm{n}=24)$, and there was no significant difference between the two groups $(\mathrm{p}>0.05)$. IgG antibodies were positive at $1 / 100$ dilution in all patients in the two groups

C. pneumoniae DNA detection rates in tissues obtained from the aorta, left ITA and atrium of the patients are given in Table 3. C. pneumoniae DNA was not detected in tissues obtained from the atrium and left ITA of 
Table 1. The preoperative demographic characteristics and operative data of the patients according to study groups.

\begin{tabular}{|c|c|c|c|}
\hline & Group 1 & Group 2 & $\mathbf{p}$ \\
\hline Age (years) & $45.3 \pm 4.1$ & $45.6 \pm 4.3$ & $>0.05$ \\
\hline $\begin{array}{c}\text { Gender } \\
\text { (Male/Female) }\end{array}$ & $20 / 3$ & $24 / 4$ & $>0.05$ \\
\hline BMI (kg/m²) & $26.6 \pm 4.3$ & $26.5 \pm 3.8$ & $>0.05$ \\
\hline EF (\%) & $55.9 \pm 10.9$ & $54 \pm 12.2$ & $>0.05$ \\
\hline Presence of DM & $9(39.1)$ & $6(21.4)$ & $>0.05$ \\
\hline Presence of HT & $12(52.2)$ & $9(32.1)$ & $>0.05$ \\
\hline Smoking history & $18(78.3)$ & $23(82.1)$ & $>0.05$ \\
\hline $\begin{array}{c}\text { Total Cholesterol } \\
(\mathrm{mg} / \mathrm{dL})\end{array}$ & $191.48 \pm 50.4$ & $185.36 \pm 38.8$ & $>0.05$ \\
\hline History of USAP & $6(26.1)$ & $11(39.3)$ & $>0.05$ \\
\hline History of MI & $16(69.6)$ & $17(60.7)$ & $>0.05$ \\
\hline Family History & $3(13)$ & $8(28.6)$ & $>0.05$ \\
\hline Presence of COPD & $1(4.3)$ & $1(3.6)$ & $>0.05$ \\
\hline Presence of PAD & $1(4.3)$ & 0 & $>0.05$ \\
\hline Presence of CRF & 0 & $1(3.6)$ & $>0.05$ \\
\hline $\begin{array}{c}\text { ACC Time } \\
\text { (minutes) }\end{array}$ & $59.75 \pm 12.6$ & $59.30 \pm 17.9$ & $>0.05$ \\
\hline $\begin{array}{l}\text { CPB Time } \\
\text { (minutes) }\end{array}$ & $114.85 \pm 20.9$ & $101.35 \pm 23.8$ & $>0.05$ \\
\hline
\end{tabular}

The values are presented as mean \pm standard deviation or number (percentages). Group 1: patients with an ascending aortic intimal thickness $<2 \mathrm{~mm}$; Group 2: patients with an ascending aortic intimal thickness $\geq 2 \mathrm{~mm}$; ACC: aortic cross clamp; BMI: body mass index; COPD: chronic obstructive pulmonary disease; CPB: cardiopulmonary bypass; CRF: chronic renal failure; DM: diabetes mellitus; EF: ejection fraction; HT: hypertension; MI: myocardial infarction; PAD: peripheral arterial disease, USAP: unstable angina pectoris.

the patients, however aortic tissues of 12 patients were positive for C. pneumoniae DNA. C. pneumoniae DNA positivity, by using PCR, was significantly higher in Group $2(35.7 \% ; \mathrm{n}=10)$, compared to Group $1(8.7 \% ; \mathrm{n}$ $=2 ; \mathrm{p}=0.024)$.

The patients were also analyzed in two groups according to C. pneumoniae DNA positivity, as $\mathrm{PCR}(+)$ Group $(\mathrm{n}=12)$, and PCR $(-)$ Group $(\mathrm{n}=39)$, and it was observed that the demographic characteristics of patients in the two groups were similar ( $p>0.05$; Table 4). No significant difference was found between the PCR $(+)$ and PCR (-) patients in terms of IgA positivity ( $p>$ $0.05)$.

\section{Discussion}

Results of case control studies published in Finland (1988) brought a new dimension to the potential etiologic relationship between the pathology and progression of chronic infections and coronary artery disease [17]. The demonstration of $C$. pneumoniae Antibodies in the atheromatous coronary artery tissue samples collected postmortem during the same years by Helsinki Cardiac Research Group in South Africa, supported the associa-
Table 2. The rates of Chlamydia pneumoniae immunoglobulin A, immunoglobulin $G$ and immunoglobulin $M$ antibody positivity.

\begin{tabular}{cccc}
\hline & $\begin{array}{c}\text { Group 1 } \\
\text { n (\%) }\end{array}$ & $\begin{array}{c}\text { Group 2 } \\
\text { n (\%) }\end{array}$ & p \\
\hline Chlamydia pneumoniae IgA & $20(87)$ & $24(85.7)$ & $>0.05$ \\
Chlamydia pneumoniae IgG & $23(100)$ & $28(100)$ & $>0.05$ \\
Chlamydia pneumoniae IgM & 0 & 0 & $>0.05$ \\
\hline
\end{tabular}

Group 1: patients with an ascending aortic intimal thickness $<2 \mathrm{~mm}$; Group 2: patients with an ascending aortic intimal thickness $\geq 2 \mathrm{~mm}$; Ig: immunoglobulin.

Table 3. The rates of Chlamydia pneumoniae DNA positivity in the tissues obtained from the aorta, internal thoracic artery and atrium of patients by polymerase chain reaction.

\begin{tabular}{cccc}
\hline & $\begin{array}{c}\text { Group 1 } \\
\text { n (\%) }\end{array}$ & $\begin{array}{c}\text { Group 2 } \\
\text { n (\%) }\end{array}$ & p \\
\hline Aorta & $2(8.7)$ & $10(35.7)$ & 0.024 \\
Internal Thoracic Artery & 0 & 0 & 0 \\
Atrium & 0 & 0 & 0 \\
\hline
\end{tabular}

Group 1: patients with an ascending aortic intimal thickness $<2 \mathrm{~mm}$; Group 2: patients with an ascending aortic intimal thickness $\geq 2 \mathrm{~mm}$.

tion of chronic C. pneumoniae infections with the formation of atherosclerosis in the blood vessels and acute myocardial infarcts [7].

Pieniazek et al. [18] found higher levels of $\operatorname{IgG}$ and IgA in the patient group (60.5\% and $61.8 \%$ respectively) whereas the corresponding figures were $26 \%$ and $29.5 \%$ in the control group. Again, Halvorsen et al. [19] found that IgA and IgG seroprevalence was significantly higher in young patients with myocardial infarction compared to controls.

In the postmortem atheromatous tissue examination of 36 cases in a study conducted in South Africa, C. pneumoniae antigens were detected in $56 \%$ of samples by histochemical staining and in all of the samples by PCR method [20].

Farsak et al. [21] compared 49 endarterectomy specimens and 39 healthy ascending aorta samples in terms of the presence of C. pneumoniae and H. pylori DNA, and observed that $C$. pneumoniae and $H$. pylori DNA positivity was $26 \%$ and $17 \%$, respectively, in the patient group. However, none of these microorganisms was encountered in the samples of the control group.

Robinson et al. [22] evaluated C. pneumoniae DNA by using PCR, in the aorta, ITA and saphenous vein tissue samples collected from 21 patients. While C. pneumoniae DNA was detected in 4 of the 6 atherosclerotic aorta samples and in 6 of the 11 atherosclerotic ITA samples, it was not detected in the saphenous vein samples and non-atherosclerotic samples. Results of this study were similar to the results of our study. We also evaluated the 
Table 4. Demographic characteristics of polymerase chain reaction $(+)$ and polymerase chain reaction $(-)$ patients.

\begin{tabular}{cccc}
\hline & PCR (+) & PCR (-) & p \\
\hline $\begin{array}{c}\text { Age (years) } \\
\text { Gender } \\
\text { (Male/Female) }\end{array}$ & $45.67 \pm 3.8$ & $45.51 \pm 4.3$ & $>0.05$ \\
BMI (kg/m $\left.\mathbf{m}^{2}\right)$ & $26.07 \pm 4.1$ & $26.7 \pm 4$ & $>0.05$ \\
Presence of DM & $4(33.3)$ & $11(28.2)$ & $>0.05$ \\
Presence of HT & $6(50)$ & $15(38.5)$ & $>0.05$ \\
$\begin{array}{c}\text { Smoking History } \\
\text { Total Cholesterol } \\
\text { (mg/dL) }\end{array}$ & $9203.58 \pm 51.2$ & $183.36 \pm 41.2$ & $>0.05$ \\
History of USAP & $5(41.7)$ & $12(30.8)$ & $>0.05$ \\
History of MI & $7(58.3)$ & $26(66.7)$ & $>0.05$ \\
Family History & $4(33.3)$ & $7(17.9)$ & $>0.05$ \\
\hline
\end{tabular}

The values are presented as mean \pm standard deviation or number (percentages). BMI: body mass index; DM: diabetes mellitus; HT: hypertension; MI: myocardial infarction; PCR: polymerase chain reaction; USAP: unstable angina pectoris

presence of $C$. pneumoniae DNA in tissue samples collected from the ascending aorta, ITA and right atrium. Similar to the present study, C. pneumoniae DNA was detected in 12 of the aorta samples collected from 51 patients in our study, but contrarily ITA and atrial tissue samples were negative for $C$. pneumoniae DNA.

Kuo et al. [8] studied the postmortem biopsy samples collected from patients aged 15 - 34 years, in the multicentered Pathobiological Determinants of Atherosclerosis in Youth (PDAY) study, and C. pneumoniae DNA was detected by using PCR in $42 \%$ of patients with atheromatous plaques in the left anterior descending (LAD) tissue samples. They emphasized that $C$. pneumoniae might be responsible for coronary pathology not only in the elderly, but in the youth as well. Davidson et al. [23], in a study for the same purpose, detected $C$. pneumoniae DNA by PCR in $23 \%$ of coronary artery samples collected postmortem from 60 individuals with an average age of 34.1 years, of whom $97 \%$ died of noncardiovascular causes. They argued that there might be a relationship between chronic $C$. pneumoniae infection and the development of early atherosclerosis and coronary artery disease. For the same purpose, we included patients under the age of 50 .

Speculative studies showing the relationship between C. pneumoniae infection and coronary pathology have also been published. Weiss et al. [13] have stated that there cannot be any relationship between $C$. pneumoniae and atherosclerosis. Ericson et al. [24], in their postmortem study, supported the hypothesis that $C$. pneumoniae intracellular infection might be related to the severity of atherosclerosis in some cases, but they found no difference between severe and mild atherosclerosis cases in terms of serum antibody titers.

We studied the presence of $C$. pneumoniae $\operatorname{IgG}, \operatorname{IgA}$ and IgM antibody at 1/100 dilution. As DNA detection would be made by PCR in all tissue samples, we did not choose to work with higher dilutions. Interestingly, while all samples were positive for IgG antibodies, they were all negative for $\operatorname{IgM}$ antibodies. IgA antibodies were positive in $86.3 \%$ of the patients, but no significant difference was detected between the two groups.

We observed the presence of nucleic acids compatible with the target series in $12(23.5 \%)$ of the tissue samples collected from the ascending aorta. $C$. pneumoniae DNA positivity rate was significantly higher in cases with increased aortic wall thickness compared to those without an increase in the thickness of the aortic wall. The positivity rate of $C$. pneumoniae DNA in ascending aortic tissue samples was lower than the rate of $50 \%$ found in a similar study by Farsak et al. [21] again, the positivity rate of $C$. pneumoniae DNA in the ascending aorta and ITA tissue samples in Robinson's study was higher than the rates observed in our study [22]. Blasi et al. [25] found the $C$. pneumoniae DNA positivity in $51 \%$ of patients with aortic aneurysm. The differences between these rates may be attributed to method-dependent reasons like PCR protocol, selection and transportation of samples, cross-reactions with the used method or other local risk factors.

In order to eradicate the chronic infections caused by C. pneumonia, comparative studies were conducted with azithromycin and doxycycline, but none of the agents was found sufficient for the eradication of $\mathrm{C}$. pneumonia infections [26-28]. Data obtained from these clinical studies should be extended to include the association between $C$. pneumoniae and atherosclerosis. Moreover, pathological mechanisms should be clearly defined to allow for the determination of the dose, treatment period and follow-up of the optimal antibiotic regimen.

\section{Conclusion}

While $C$. pneumoniae DNA was not detected in the atrial and left ITA samples of young patients, the positivity rate was $23.5 \%$ in the ascending aorta, a region prone to the development of atherosclerosis. The intimal thickness was found to be increased in most of these patients, but there was no relationship between antibody titers and DNA positivity. Although our study suggested a possible association between $C$. pneumoniae and atherosclerosis, the question whether the colonization of $C$. pneumoniae in the vessels and prior pneumonia infections are the triggering factors for atherosclerotic lesions or are involved as a superinfection, could not be clarified. Therefore, 
case-control studies with larger samples aimed at defining the relationship between $C$. pneumoniae and atherosclerosis should be conducted.

\section{REFERENCES}

[1] V. Fuster, "Epidemic of Cardiovascular Disease and Stroke: The Three Main Challenges," Circulation, Vol. 99, No. 9, 1999, pp. 1132-1137. doi:10.1161/01.CIR.99.9.1132

[2] C. H. Hennekens, "Increasing Burden of Cardiovascular Disease: Current Knowledge and Future Directions for Research on Risk Factors," Circulation, Vol. 97, No. 19, 1998, pp. 1095-1102. doi:10.1161/01.CIR.97.11.1095

[3] G. Noll, "Pathogenesis of Atherosclerosis: A Possible Relation of Infection," Atherosclerosis, Vol. 140, Supplement 1, 1998, pp. 3-9. doi:10.1016/S0021-9150(98)00113-0

[4] S. Gupta and A. J. Camm, "Chlamydia pneumoniae and Coronary Heart Disease," British Medical Journal, Vol. 314, No. 7097, 1997, pp. 1778-1779. doi:10.1136/bmj.314.7097.1778

[5] C. Bartels, M. Maass, G. Bein, et al., "Detection of Chlamydia pneumoniae but Not Cytomegalovirus in Occluded Saphenous Vein Coronary Artery Bypass Grafts," Circulation, Vol. 99, No. 7, 1999, pp. 879-882. doi:10.1161/01.CIR.99.7.879

[6] Y. Wong, M. Thomas, V. Tsang, et al., "The Prevalence of Chlamydia pneumoniae in Atherosclerotic and Nonatherosclerotic Blood Vessels of Patients Attending for Redo and First Time Coronary Artery Bypass Graft Surgery," Journal of the American College of Cardiology, Vol. 33, No. 1, 1999, pp. 152-156. doi:10.1016/S0735-1097(98)00547-6

[7] P. Saikku, M. Leinonen, L. Tenkanen, et al., "Chronic Chlamydia pneumoniae Infection as a Risk Factor for Coronary Heart Disease in the Helsinki Heart Study," Annals of Internal Medicine, Vol. 116, No. 4, 1992, pp. 273-278. doi:10.7326/0003-4819-116-4-273

[8] C. C. Kuo, J. T. Grayston, L. A. Campbell, et al., "Chlamydia Pneumoniae (TWAR) in Coronary Arteries of Young Adults (15 - 34 Years Old)," Proceedings of the National Academy of Sciences of the United States of America, Vol. 92, No. 15, 1995, pp. 6911-6914. doi:10.1073/pnas.92.15.6911

[9] J. T. Grayston, C. C. Kuo, A. S. Coulson, et al., "Chlamydia Pneumoniae (TWAR) in Atherosclerosis of the Carotid Artery," Circulation, Vol. 92, No. 12, 1995, pp. 3397-3400. doi:10.1161/01.CIR.92.12.3397

[10] C. C. Kuo, A. M. Gown, E. P. Benditt, et al., "Detection of Chlamydia pneumoniae in Aortic Lesions of Atherosclerosis by Immunocytochemical Stain," Arteriosclerosis, Thrombosis, and Vascular Biology, Vol. 13, No. 10, 1993, pp. 1501-1504. doi:10.1161/01.ATV.13.10.1501

[11] S. Gupta and E. W. Leatham, "The Relation between Chlamydia pneumoniae and Atherosclerosis," Heart, Vol. 77, No. 1, 1997, pp. 7-8.

[12] G. Ong, B. J. Thomas, A. O. Mansfield, et al., "Detection and Widespread Distribution of Chlamydia pneumoniae in the Vascular System and Its Possible Implications," Journal of Clinical Pathology, Vol. 49, No. 2, 1996, pp. 102-106. doi:10.1136/jcp.49.2.102

[13] S. M. Weiss, P. M. Roblin, C. A. Gaydos, et al., "Failure to Detect Chlamydia pneumoniae in Coronary Atheromas of Patients Undergoing Atherectomy," The Journal of Infectious Diseases, Vol. 173, No. 4, 1996, pp. 957-962. doi:10.1093/infdis/173.4.957

[14] K. Matsuyama, T. Goto, T. Baba, et al., "Echocardiographic and Pathological Evaluation of Atherosclerosis in the Ascending Aorta during Coronary Artery Bypass Grafting," Anesthesia \& Analgesia, Vol. 90, No. 6, 2000, pp. 1262-1268. doi:10.1097/00000539-200006000-00002

[15] T. H. Wareing, V. G. Davila-Roman, B. Barzilai, et al., "Management of the Severely Atherosclerotic Ascending Aorta during Cardiac Operations. A Strategy for Detection and Treatment," The Journal of Thoracic and Cardiovascular Surgery, Vol. 103, No. 3, 1992, pp. 453-462.

[16] M. L. Tondella, D. F. Talkington, B. P. Holloway, et al., "Development and Evaluation of Real-Time PCR-Based Fluorescence Assays for Detection of Chlamydia Pneumoniae," Journal of Clinical Microbiology, Vol. 40, No. 2, 2002, pp. 575-583. doi:10.1128/JCM.40.2.575-583.2002

[17] P. Saikku, M. Leinonen, K. Mattila, et al., "Serological Evidence of an Association of a Novel Chlamydia, TWAR, with Chronic Coronary Heart Disease and Acute Myocardial Infarction," Lancet, Vol. 332, No. 8618, 1988, pp. 983-986. doi:10.1016/S0140-6736(88)90741-6

[18] P. Pieniazek, E. Karczewska, E. Stepień, et al., "Incidence of Chlamydia pneumoniae Infection in Patients with Coronary Artery Disease Subjected to Angioplasty or Bypass Surgery," Medical Science Monitor, Vol. 7, No. 5, 2001, pp. 995-1001.

[19] D. S. Halvorsen, T. Børvik, I. Njølstad, et al., "Chlamydia Pneumoniae IgA- and IgG Antibodies in Young Survivors of Myocardial Infarction. A Comparison of Antibody Detection by a Microimmunofluorescence Test and an Enzyme Immunoassay," Journal of Internal Medicine, Vol. 251, No. 2, 2002, pp. 142-147. doi:10.1046/j.1365-2796.2002.00942.x

[20] L. A. Campbell, E. R. O'Brien, A. L. Cappuccio, et al., "Detection of Chlamydia pneumoniae TWAR in Human Coronary Atherectomy Tissues," The Journal of Infectious Diseases, Vol. 172, No. 2, 1995, pp. 585-588. doi:10.1093/infdis/172.2.585

[21] B. Farsak, A. Yildirir, Y. Akyön, et al., "Detection of Chlamydia pneumoniae and Helicobacter pylori DNA in Human Atherosclerotic Plaques by PCR," Journal of Clinical Microbiology, Vol. 38, No. 12, 2000, pp. 44084411.

[22] D. Taylor-Robinson, B. J. Thomas, R. Goldin, et al., "Chlamydia pneumoniae in Infrequently Examined Blood Vessels," Journal of Clinical Pathology, Vol. 55, No. 3, 2002, pp. 218-220. doi:10.1136/jcp.55.3.218

[23] M. Davidson, C. C. Kuo, J. P. Middaugh, et al., "Confirmed Previous Infection with Chlamydia pneumoniae (TWAR) and Its Presence in Early Coronary Atheroscle- 
rosis," Circulation, Vol. 98, No. 7, 1998, pp. 628-633. doi:10.1161/01.CIR.98.7.628

[24] K. Ericson, T. G. Saldeen, O. Lindquist, et al., "Relationship of Chlamydia pneumoniae Infection to Severity of Human Coronary Atherosclerosis," Circulation, Vol. 101, No. 22, 2000, pp. 2568-2571.

doi:10.1161/01.CIR.98.7.628

[25] F. Blasi, F. Denti, M. Erba, et al., "Detection of Chlamydia Pneumoniae but Not Helicobacter pylori in Atherosclerotic Plaques of Aortic Aneurysms," Journal of Clinical Microbiology, Vol. 34, No. 11, 1996, pp. 2766-2769.

[26] J. Sinisalo, K. Mattila, M. S. Nieminen, et al., "The Effect of Prolonged Doxycycline Therapy on Chlamydia Pneumoniae Serological Markers, Coronary Heart Disease
Risk Factors and Forearm Basal Nitric Oxide Production," Journal of Antimicrobial Chemotherapy, Vol. 41, No. 1, 1998, pp. 85-92. doi:10.1093/jac/41.1.85

[27] J. B. Muhlestein, J. L. Anderson, J. F. Carlquist, et al., "Randomized Secondary Prevention Trial of Azithromycin in Patients with Coronary Artery Disease: Primary Clinical Results of the ACADEMIC Study," Circulation, Vol. 102, No. 15, 2000, pp. 1755-1760. doi:10.1161/01.CIR.102.15.1755

[28] L. A. Jackson, "Description and Status of the Azithromycin and Coronary Events Study (ACES)," The Journal of Infectious Diseases, Vol. 181, Supplement 3, 2000, pp. 579-581. doi:10.1086/315628 